\title{
Association between longer duration of citrate accumulation and 90-day mortality of acute-on-chronic liver failure
}

\author{
Ming Wang ${ }^{\dagger}$, Yuanji $\mathrm{Ma}^{\dagger}$, Lingyao $\mathrm{Du}^{\dagger}$, Hong Tang $^{*}$ and Lang Bai ${ }^{*}$ (D
}

Regional citrate anticoagulation (RCA) is an optional anticoagulant for plasma adsorption (PA) plus plasma exchange (PE) therapy in patients with acute-on-chronic liver failure (ACLF), but with risk of transient citrate accumulation due to plasma and citrate [1]. Regardless of the anticoagulants: heparin or citrate, some patients would suffer from longer duration of citrate accumulation (LDCA), defined as the presence of citrate accumulation $2 \mathrm{~h}$ after PA plus PE therapy with RCA $[1,2]$. However, whether citrate accumulation itself would lead to poor prognosis remains uncertain.

We conducted a retrospective study based on medical records to assess the association between LDCA and prognosis of hepatitis B virus (HBV)-related ACLF. Methods and some data from this cohort have been published already [2]. We kept to follow-up these patients for another 90 days after acquiring further ethical approval and registered this study with ChiCTR-OON-17013631. HBV-ACLF was diagnosed according to COSSH ACLF criteria [3]. Citrate accumulation was defined as the ratio of total calcium $\left(\mathrm{Ca}_{\text {tot }}\right)$ to ionized calcium $\left(\mathrm{Ca}_{\text {ion }}\right),\left(\mathrm{Ca}_{\text {tot }} /\right.$ $\left.\mathrm{Ca}_{\text {ion }}\right)$, over or equal to $2.5\left(\mathrm{Ca}_{\text {tot }} / \mathrm{Ca}_{\text {ion }} \geq 2.5\right)[1,2]$. Cox proportional hazards models were applied to evaluate the association of LDCA with outcome.

From January 2018 to December 2019, we reviewed the data of 258 patients who fulfilled the HBV-ACLF

\footnotetext{
*Correspondence: htang6198@hotmail.com; pangbailang@163.com ${ }^{\dagger}$ Ming Wang, Yuanji Ma and Lingyao Du have contributed equally to this work

Center of Infectious Diseases, West China Hospital of Sichuan University, No. 37 GuoXue Xiang, Wuhou District, Chengdu 610041, China
}

criteria and received PA plus PE therapy with RCA. LDCA patients $(N=76)$ were more often female and older and had worse severity of disease condition than non-LDCA patients $(N=182)$ (Table 1$)$. There was no significant difference in indicators, such as intracorporeal and extracorporeal $\mathrm{Ca}_{\text {tot }}$ and $\mathrm{Ca}_{\text {ion }}$, representing patients receiving similar RCA during and after the first session of PA plus PE therapy with RCA.

The 90-day mortality of LDCA patients was much higher than that of non-LDCA patients $(63.2 \%$ vs. $32.4 \%$, $\log$-rank $p<0.001)$. Compared with non-LDCA patients, LDCA patients had much higher 90-day mortality risk (crude hazard ratio (HR) (95\% confidence interval (CI)), 2.62 (1.79-3.84)) (Table 2). However, no significant differences in 90-day mortality risk were observed with the Cox proportional hazards models established with LDCA, age, gender, liver cirrhosis, HBV DNA, other coexisting liver diseases, comorbidities, and disease severity (Model 1, COSSH ACLF score; Model 2, CLIF-C ACLF score; Model 3, AARC ACLF score; Model 4, MELD score): Model 1 adjusted HR (95\% CI), 1.07 (0.66-1.73); Model 2, 1.49 (0.95-2.36); Model 3, 1.41 (0.90-2.22); Model 4, 1.05 (0.65-1.72) (Table 2). Similarly, no significant differences in 90-day mortality risk were observed with similar Cox models established with citrate level indicators (Model $5, \mathrm{Ca}_{\text {tot }} / \mathrm{Ca}_{\text {ion }} \geq 2.25$; Model $6, \mathrm{Ca}_{\text {tot }} /$ $\mathrm{Ca}_{\text {ion }}$; Model 7 , anion gap), disease severity (COSSH ACLF score), and the others mentioned above: Model 5, 1.28 (0.78-2.08); Model 6, 1.56 (0.74-3.27); Model 7, 1.06 $(0.97-1.16)$. The disease severity was the independent risk factor of 90 -day mortality (Model $1-7$, all adjusted $\mathrm{HR}>1$, all $p<0.001$ ).

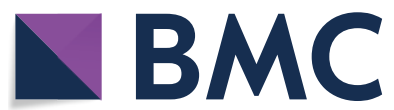

(c) The Author(s) 2021. Open Access This article is licensed under a Creative Commons Attribution 4.0 International License, which permits use, sharing, adaptation, distribution and reproduction in any medium or format, as long as you give appropriate credit to the original author(s) and the source, provide a link to the Creative Commons licence, and indicate if changes were made. The images or other third party material in this article are included in the article's Creative Commons licence, unless indicated otherwise in a credit line to the material. If material is not included in the article's Creative Commons licence and your intended use is not permitted by statutory regulation or exceeds the permitted use, you will need to obtain permission directly from the copyright holder. To view a copy of this licence, visit http://creativecommons.org/licenses/by/4.0/. The Creative Commons Public Domain Dedication waiver (http://creativecommons.org/publicdomain/zero/1.0/) applies to the data made available in this article, unless otherwise stated in a credit line to the data. 
Table 1 Characteristics of ACLF patients with or without LDCA

\begin{tabular}{|c|c|c|c|}
\hline & Patients with LDCA $(N=76)$ & $\begin{array}{l}\text { Patients without LDCA } \\
(N=182)\end{array}$ & $p$ \\
\hline Female & $25(32.9 \%)$ & $12(6.6 \%)$ & $<0.001$ \\
\hline Age(years) & $52.2 \pm 10.9$ & $43.8 \pm 11.2$ & $<0.001$ \\
\hline Liver cirrhosis & $61(80.3 \%)$ & $141(77.5 \%)$ & 0.620 \\
\hline Causes of liver disease & & & 0.963 \\
\hline HBV infection only & $57(75.0 \%)$ & $137(75.3 \%)$ & \\
\hline HBV infection plus other causes & $19(25.0 \%)$ & $45(24.7 \%)$ & \\
\hline Comorbidities & & & 0.112 \\
\hline No & $59(77.6 \%)$ & $156(85.7 \%)$ & \\
\hline Yes & $17(22.4 \%)$ & $26(14.3 \%)$ & \\
\hline \multicolumn{4}{|l|}{ Disease severity assessment } \\
\hline COSSHACLF score & $7.1 \pm 1.0$ & $6.3 \pm 0.8$ & $<0.001$ \\
\hline CLIF-C ACLF score & $38.9 \pm 6.9$ & $32.7 \pm 6.5$ & $<0.001$ \\
\hline AARCACLF score & $10.7 \pm 1.6$ & $9.6 \pm 1.5$ & $<0.001$ \\
\hline MELD score & $29.8 \pm 5.5$ & $25.7 \pm 3.9$ & $<0.001$ \\
\hline \multicolumn{4}{|l|}{ Laboratory examination } \\
\hline PT-INR & $2.36(1.95-2.81)$ & $2.06(1.75-2.44)$ & 0.009 \\
\hline Serum creatinine $(x$ ULN) & $0.97(0.80-1.32)$ & $0.80(0.65-0.88)$ & $<0.001$ \\
\hline Total bilirubin $(\mu \mathrm{mol} / \mathrm{L})$ & $431.0 \pm 135.4$ & $421.9 \pm 120.0$ & 0.495 \\
\hline Direct bilirubin to total bilirubin ratio & $0.75(0.70-0.82)$ & $0.80(0.73-0.86)$ & 0.009 \\
\hline Alanine aminotransferase (IU/L) & $140(56-300)$ & $124(66-245)$ & 0.891 \\
\hline Aspartate aminotransferase (IU/L) & $139(76-227)$ & $116(88-192)$ & 0.133 \\
\hline Aspartate aminotransferase to alanine aminotransferase ratio & $1.13(0.65-1.92)$ & $1.06(0.64-1.53)$ & 0.495 \\
\hline Albumin (g/L) & $31.8 \pm 3.6$ & $31.8 \pm 4.0$ & 0.742 \\
\hline Albumin to globulin ratio & $1.2 \pm 0.4$ & $1.2 \pm 0.4$ & 0.041 \\
\hline Ammonia (mmol/L) & $77.6(58.0-117.8)$ & $79.1(60.9-110.2)$ & 0.891 \\
\hline Lactate $(\mathrm{mmol} / \mathrm{L})$ & $2.98(2.03-3.89)$ & $2.40(1.90-3.00)$ & $<0.001$ \\
\hline Serum sodium (mmol/L) & $130.7 \pm 15.8$ & $134.5 \pm 4.1$ & 0.009 \\
\hline Serum potassium (mmol/L) & $3.44 \pm 0.55$ & $3.46 \pm 0.58$ & 0.866 \\
\hline Serum chloride (mmol/L) & $93.9 \pm 5.6$ & $97.3 \pm 4.4$ & $<0.001$ \\
\hline Hemoglobin (g/L) & $111 \pm 18$ & $122 \pm 20$ & 0.002 \\
\hline Platelets $\left(\times 10^{9} / \mathrm{L}\right)$ & $83(48-114)$ & $91(64-124)$ & 0.180 \\
\hline White blood cells $\left(\times 10^{9} / \mathrm{L}\right)$ & $7.87 \pm 4.08$ & $7.47 \pm 3.48$ & 0.495 \\
\hline Intracorporeal $\mathrm{Ca}_{\text {tot }}$ before PA therapy (mmol/L) & $2.16 \pm 0.15$ & $2.13 \pm 0.13$ & 0.133 \\
\hline Intracorporeal $\mathrm{Ca}_{\text {ion }}$ before PA therapy $(\mathrm{mmol} / \mathrm{L})$ & $1.020 \pm 0.089$ & $1.051 \pm 0.076$ & 0.123 \\
\hline Intracorporeal $\mathrm{Ca}_{\text {tot }}$ during PA therapy $(\mathrm{mmol} / \mathrm{L})$ & $2.06 \pm 0.21$ & $1.97 \pm 0.24$ & 0.595 \\
\hline Intracorporeal $\mathrm{Ca}_{\text {ion }}$ during PA therapy $(\mathrm{mmol} / \mathrm{L})$ & $0.749 \pm 0.098$ & $0.808 \pm 0.109$ & 0.262 \\
\hline Extracorporeal $\mathrm{Ca}_{\text {ion }}$ during PA therapy $(\mathrm{mmol} / \mathrm{L})$ & $0.167(0.132-0.233)$ & $0.184(0.145-0.238)$ & 0.345 \\
\hline Intracorporeal $\mathrm{Ca}_{\text {tot }} 2 \mathrm{~h}$ after PE therapy $(\mathrm{mmol} / \mathrm{L})$ & $2.65 \pm 0.26$ & $2.46 \pm 0.18$ & $<0.001$ \\
\hline Intracorporeal $\mathrm{Ca}_{\text {ion }} 2 \mathrm{~h}$ after PE therapy (mmol/L) & $0.962 \pm 0.100$ & $1.103 \pm 0.081$ & $<0.001$ \\
\hline $\mathrm{Ca}_{\text {tot }} / \mathrm{Ca}_{\text {ion }} 2 \mathrm{~h}$ after PE therapy & $2.70(2.58-2.90)$ & $2.22(2.14-2.32)$ & $<0.001$ \\
\hline Anion gap $2 \mathrm{~h}$ after PE therapy (mmol/L) & $7.67 \pm 2.90$ & $6.85 \pm 2.34$ & 0.010 \\
\hline \multicolumn{4}{|l|}{ DPMAS plus PE therapy with RCA } \\
\hline Sessions & $3.0(2.3-5.0)$ & $4.0(3.0-6.0)$ & 0.204 \\
\hline Days from the first to the last sessions & $7.0(4.0-14.0)$ & $8.0(5.0-14.0)$ & 0.292 \\
\hline 90-day prognosis (death) & $48(63.2 \%)$ & $59(32.4 \%)$ & $<0.001$ \\
\hline
\end{tabular}

Quantitative data are represented as mean \pm SD (normally distributed data) or median (interquartile range) (non-normally distributed data) and compared by Mood's median test. Qualitative data are represented as frequencies (proportion) and compared by Chi-squared test

ACLF, Acute-on-chronic liver failure; LDCA, longer duration of citrate accumulation; HBV, hepatitis B virus; COSSH, Chinese Group on the Study of Severe Hepatitis B; CLIF-C, European Association for the Study of the Liver-Chronic Liver Failure-Consortium; AARC, APASL ACLF Research Consortium; APASL, Asian Pacific Association for the Study of the Liver; MELD, Model for End-Stage Liver Disease; PT-INR, international normalized ratio (INR) of prothrombin time (PT); ULN, upper limit of normal; $\mathrm{PA}$, plasma adsorption; $\mathrm{PE}$, plasma exchange; $\mathrm{Ca}_{\text {tot }}$, total calcium; $\mathrm{Ca}_{\text {ion, }}$, ionized calcium; $\mathrm{Ca}_{\text {tot }} / \mathrm{Ca}_{\text {ion }}, \mathrm{Ca}_{\text {tot }}$ to $\mathrm{Ca}_{\text {ion }}$ ratio 
Table 2 LDCA and other factors associated with risk of 90-day mortality in ACLF patients

\begin{tabular}{|c|c|c|c|c|c|}
\hline & \multirow[t]{2}{*}{ Crude HR $(95 \% \mathrm{Cl})$} & \multicolumn{4}{|c|}{ Adjusted $\mathrm{HR}^{\boldsymbol{\Delta}}(95 \% \mathrm{Cl})$} \\
\hline & & Model 1 & Model 2 & Model 3 & Model 4 \\
\hline \multicolumn{6}{|l|}{ LDCA } \\
\hline No & 1 & 1 & 1 & 1 & 1 \\
\hline Yes & $2.62(1.79-3.84)^{* * *}$ & $1.07(0.66-1.73)$ & $1.49(0.95-2.36)$ & $1.41(0.90-2.22)$ & $1.05(0.65-1.72)$ \\
\hline Age (years) & $1.03(1.01-1.05)^{* * *}$ & $0.99(0.97-1.02)$ & $0.97(0.94-0.99)^{* *}$ & $1.02(1.00-1.04)$ & $1.01(0.99-1.03)$ \\
\hline \multicolumn{6}{|l|}{ Gender } \\
\hline Male & 1 & 1 & 1 & 1 & 1 \\
\hline Female & $1.84(1.15-2.94)^{*}$ & $1.24(0.73-2.08)$ & $1.04(0.62-1.76)$ & $1.25(0.74-2.09)$ & $1.81(1.07-3.08)^{*}$ \\
\hline \multicolumn{6}{|l|}{ Liver cirrhosis } \\
\hline No & 1 & 1 & 1 & 1 & 1 \\
\hline Yes & $2.51(1.37-4.57)^{* *}$ & $1.66(0.90-3.08)$ & $2.14(1.17-3.95)^{*}$ & $2.20(1.19-4.06)^{*}$ & $1.97(1.07-3.65)^{*}$ \\
\hline HBV DNA $(\log 10 \mathrm{IU} / \mathrm{mL})$ & $0.98(0.89-1.09)$ & $1.02(0.92-1.13)$ & $1.00(0.90-1.12)$ & $1.00(0.90-1.12)$ & $1.01(0.90-1.13)$ \\
\hline \multicolumn{6}{|l|}{ Etiology } \\
\hline HBV infection only & 1 & 1 & 1 & 1 & 1 \\
\hline HBV infection plus other causes & $0.93(0.60-1.45)$ & $1.07(0.68-1.69)$ & $1.07(0.68-1.68)$ & $1.06(0.67-1.67)$ & $0.82(0.51-1.29)$ \\
\hline \multicolumn{6}{|l|}{ Comorbidity } \\
\hline No & 1 & 1 & 1 & 1 & 1 \\
\hline Yes & $1.86(1.20-2.90)^{* *}$ & $1.74(1.05-2.87)^{*}$ & $1.56(0.96-2.55)$ & $1.60(0.98-2.61)$ & $1.75(1.06-2.90)^{*}$ \\
\hline \multicolumn{6}{|l|}{ Disease severity } \\
\hline COSSH ACLFscore & $2.78(2.31-3.34)^{* * *}$ & $2.72(2.17-3.40)^{* * *}$ & - & - & - \\
\hline CLIF-C ACLF score & $1.13(1.09-1.16)^{* * *}$ & - & $1.15(1.10-1.19)^{* * *}$ & - & - \\
\hline AARCACLF score & $1.60(1.41-1.82)^{* * *}$ & - & - & $1.59(1.38-1.83)^{* * *}$ & - \\
\hline MELD score & $1.16(1.12-1.20)^{* * *}$ & - & - & - & $1.17(1.12-1.22)^{* * *}$ \\
\hline
\end{tabular}

HBV infection plus other causes ${ }^{-}$: the ones having HBV infection plus any one of other co-existing liver diseases was classified to this subgroup

Comorbidity : the ones having any one of comorbidities were classified as the comorbidity group

Adjusted $\mathrm{HR}^{\wedge}$ : multivariable Cox regression analysis includes LDCA (yes vs no), age (continuous years), gender (female vs male), liver cirrhosis (yes vs no), HBV DNA (continuouslog $10 \mathrm{IU} / \mathrm{mL}$ ), other co-existing liver diseases (viral infections other than hepatitis B virus, alcoholic liver disease, non-alcoholic fatty liver, immune related liver disease, drug induced liver injury, and other liver diseases), comorbidities (chronic obstructive pulmonary disease, diabetes mellitus, coronary heart disease, primary hypertension, chronic kidney disease, and other chronic diseases), and disease severity (model 1, COSSH ACLF score; model 2, CLIF-C ACLF score; model 3, AARC ACLF score; model 4, MELD score)

ACLF, Acute-on-chronic liver failure; LDCA, longer duration of citrate accumulation; $\mathrm{HR}$, hazard ratio; $\mathrm{Cl}$, confidence interval; COSSH, Chinese Group on the Study of Severe Hepatitis B; CLIF-C, European Association for the Study of the Liver-Chronic Liver Failure-Consortium; AARC, APASL ACLF Research Consortium; APASL, Asian Pacific Association for the Study of the Liver; MELD, Model for End-Stage Liver Disease

${ }^{* * *} p<0.001 ;{ }^{* *} p<0.01 ;{ }^{*} p<0.05$

Our study proved that ACLF patients with LDCA would suffer higher 90-day mortality. This finding was in accordance with the results in critically ill patients undergoing continuous renal replacement therapy with RCA [4]. However, no significant differences in 90-day mortality risk were found in ACLF patients with or without LDCA. As RCA brings no alteration of pro- and anti-coagulation function and ACLF patients have rebalanced but fragile coagulation function $[1,5]$, our new results would support the use of RCA with caution in ACLF patients. Adequate training, experienced operation, and well-developed safety protocols would further expand indications of RCA [6].

Our study for the first time assessed the association between LDCA and prognosis in ACLF patients treated with PA plus PE therapy with RCA. There were limitations: monocentric retrospective design, only HBVALCF cases, and applying $\mathrm{Ca}_{\text {tot }} / \mathrm{Ca}_{\text {ion }}$ instead of directly measuring plasma citrate concentration to reflect citrate accumulation.

\footnotetext{
Abbreviations

AARC: Asian Pacific Association for the Study of the Liver-ACLF Research Consortium; ACLF: Acute-on-chronic liver failure; $\mathrm{Ca}_{\text {tot }}$ : Total calcium; $\mathrm{Ca}_{\text {ion }}$ : lonized calcium; Cl: Confidence interval; CLIF-C: European Association for the Study of the Liver-Chronic Liver Failure-Consortium; COSSH: Chinese Group on the Study of Severe Hepatitis B; HBV: Hepatitis B virus; HR: Hazard ratio; LDCA: Longer duration of citrate accumulation; MELD: Model for end-stage liver disease; PA: Plasma adsorption; PE: Plasma exchange; RCA: Regional citrate anticoagulation.
} 


\section{Acknowledgements}

We thank all patients participating in this study for their understanding and recognition of our work.

\section{Authors' contributions}

WM, MYJ and DLY contributed to statistical analysis, drafting of the manuscript, and interpretation of data. MYJ and BL had full access to all of the data in the study and take responsibility for the integrity of the data and the accuracy of the data analysis. BL and TH contributed to study concept and design and critical revision of the manuscript for important intellectual content. All authors read and approved the final manuscript.

\section{Funding}

This work was supported by grants from the 1.3.5 project for disciplines of excellence-Clinical Research Incubation Project, West China Hospital, Sichuan University (ZYJC21014), the Beijing iGandan Foundation (RGGJJ2021-037), and the National Science and Technology Major Project for major infectious diseases such as AIDS and viral hepatitis prevention and control (2018ZX10715-003).

\section{Availability of data and materials}

The datasets used and/or analyzed during the current study are available from the corresponding author on reasonable request.

\section{Declarations}

\section{Ethics approval and consent to participate}

Approval for this study was obtained from the Biomedical Research Ethics Committee of West China Hospital of Sichuan University (No. 2020-650). All study components were performed according to the ethical standards laid down in the 1964 Declaration of Helsinki and its later amendments. Informed consent was not obtained because of retrospective design.

\section{Consent for publication}

Not applicable.

\section{Competing interests}

The authors declare to have no competing interests.
Received: 28 October 2021 Accepted: 8 November 2021

Published online: 11 November 2021

\section{References}

1. Ma Y, Chen F, Xu Y, Wang M, Zhou T, Lu J, et al. Safety and efficacy of regional citrate anticoagulation during plasma adsorption plus plasma exchange therapy for patients with acute-on-chronic liver failure: a pilot study. Blood Purif. 2019;48:223-32.

2. Ma Y, Chen F, Liu C, Xu Y, Wang M, Zhou T, et al. A novel predictive score for citrate accumulation among patients receiving artificial liver support system therapy with regional citrate anticoagulation. Sci Rep. 2020;10:12861.

3. Wu T, Li J, Shao L, Xin J, Jiang L, Zhou Q, et al. Development of diagnostic criteria and a prognostic score for hepatitis B virus-related acute-onchronic liver failure. Gut. 2018;67:2181-91.

4. Khadzhynov D, Schelter C, Lieker I, Mika A, Staeck O, Neumayer HH, et al. Incidence and outcome of metabolic disarrangements consistent with citrate accumulation in critically ill patients undergoing continuous venovenous hemodialysis with regional citrate anticoagulation. J Crit Care. 2014;29:265-71.

5. Wiegele M, Adelmann D, Dibiasi C, Pausch A, Baierl A, Schaden E. Monitoring of enoxaparin during hemodialysis covered by regional citrate anticoagulation in acute kidney injury: a prospective cohort study. J Clin Med. 2021;1010:4491.

6. Schneider AG, Joannes-Boyau O. Regional citrate anticoagulation for CRRT: still hesitating. Anaesth Crit Care Pain Med. 2021:40:100855.

\section{Publisher's Note}

Springer Nature remains neutral with regard to jurisdictional claims in published maps and institutional affiliations.
Ready to submit your research? Choose BMC and benefit from:

- fast, convenient online submission

- thorough peer review by experienced researchers in your field

- rapid publication on acceptance

- support for research data, including large and complex data types

- gold Open Access which fosters wider collaboration and increased citations

- maximum visibility for your research: over 100M website views per year

At BMC, research is always in progress.

Learn more biomedcentral.com/submissions 